\title{
C5a-induced Expression of P-selectin in Endothelial Cells
}

\author{
Kimberty E. Foreman, ${ }^{\star \ddagger}$ Ara A. Vaporciyan, ${ }^{\ddagger}$ Brian K. Bonish, ${ }^{\ddagger}$ Michael L. Jones, ${ }^{\ddagger}$ Kent J. Johnson, ${ }^{\star \ddagger}$ \\ M. Michael Glovsky, ${ }^{6}$ Susan M. Eddy, ${ }^{\ddagger}$ and Peter A. Ward ${ }^{\ddagger}$ \\ * Parke-Davis Research Division of Warner-Lambert Company, Ann Arbor, Michigan 48105; ${ }^{\ddagger}$ Department of Pathology, \\ University of Michigan Medical School, Ann Arbor, Michigan 48109-0602; and ${ }^{\S}$ Asthma and Allergy Center, \\ Huntington Memorial Hospital, Pasadena, California 91105-3022
}

\begin{abstract}
Human umbilical vein endothelial cells have recently been shown to respond to C5a with increases in intracellular $\mathrm{Ca}^{2+}$, production of D-myo-inositol 1,4,5-triphosphate and superoxide anion generation. In the current studies, C5a has been found to cause in a time- and dose-dependent manner rapid expression of endothelial P-selectin, secretion of von Willebrand factor, and adhesiveness for human neutrophils. The effects of C5a in P-selectin expression and adhesiveness of neutrophils were similar to the effects of histamine and thrombin on endothelial cells. The adhesiveness of C5a-stimulated endothelium for neutrophils was blocked by anti-P-selectin, but not by antibodies to intercellular adhesion molecule 1, E-selectin, or CD18. A cell-based ELISA technique has confirmed upregulation of P-selectin in endothelial cells exposed to C5a. Binding of C5a to endothelial cells has been demonstrated, with molecules bound being $\sim 10 \%$ of those binding to neutrophils. By a reverse transcriptase-PCR technique, endothelial cells have been shown to contain mRNA for the C5a receptor. These data suggest that C5a may be an important inflammatory mediator for the early adhesive interactions between neutrophils and endothelial cells in the acute inflammatory response. ( $\mathrm{J}$. Clin. Invest. 1994. 94:1147-1155.) Key words: adhesion • complement • endothelial cells • neutrophils • receptors
\end{abstract}

\section{Introduction}

During acute inflammation, neutrophils first adhere to vascular endothelium and then migrate into the surrounding tissues. It has been proposed that at least three distinct steps are involved in neutrophil recruitment $(1,2)$. First, there must be "activation" of the endothelium, defined as appearance of adhesionpromoting factors. A transient and reversible intermittent adhesion results in the "rolling" of unactivated neutrophils along the surface of activated endothelium. This is followed by the firm adhesion of neutrophils to endothelial cells. At some point, either before or after this adhesive interaction with the endothelium, neutrophils appear to become activated. Finally, neutro-

Address correspondence to Peter A. Ward, M.D., The University of Michigan Medical School, Department of Pathology, 1301 Catherine Street, Box 0602, Ann Arbor, MI 48109-0602.

Received for publication 14 February 1994 and in revised form 6 May 1994.

J. Clin. Invest.

(C) The American Society for Clinical Investigation, Inc 0021-9738/94/09/1147/09 \$2.00

Volume 94, September 1994, 1147-1155 phils migrate through endothelial cell junctions into the surrounding tissue. The initial rolling of the neutrophils along the endothelial cell surface appears to be mediated by members of the selectin family of adhesion molecules (L-, E-, and P-selectin) (3). The $\beta_{2}$ integrins (CD11a/CD18, CD11b/CD18, and CD11c/CD18) expressed on neutrophils are believed to mediate firm adhesion through interaction with intercellular adhesion molecules (ICAM) 1 and $2^{1}$ expressed on the activated endothelium (3). Recently it has been suggested that the next step involves interaction of neutrophils with platelet-endothelial cell adhesion factor present in basolateral junctions of endothelial cells $(4,5)$. The final step, migration of the neutrophils into the area of inflammation, may be mediated by chemotactic factors such as C5a, LTB4, and platelet-activating factor (6).

$P$-selectin was originally identified as an $\alpha$-granule membrane protein in platelets capable of being translocated to the cell membrane after platelet activation and degranulation (7, 8 ). Also, P-selectin is produced constitutively and stored intracellularly in Weibel-Palade bodies of human umbilical vein endothelial cells (HUVECs) $(9,10)$. Exposure of endothelium to mediators such as thrombin, histamine, $\mathrm{H}_{2} \mathrm{O}_{2}$, or the complement membrane attack complex $(\mathrm{C} 5 \mathrm{~b}-\mathrm{C} 9)$ results in rapid upregulation of $\mathrm{P}$-selectin expression on the cell surface (9, 11-13). Except for $\mathrm{H}_{2} \mathrm{O}_{2}$, the induced expression of P-selectin is short lived, peaking at 5-10 min and returning to basal levels within 30-60 min due, apparently, to internalization of P-selectin (11). In the case of $\mathrm{H}_{2} \mathrm{O}_{2}$ stimulation of endothelial cells, P-selectin expression appears to be stable (12). Unactivated human blood neutrophils adhere in a CD18-independent manner to endothelial cells stimulated under conditions known to promote P-selectin expression (12, 14-16). Recent studies suggest that glycoproteins with sialylated $O$-linked oligosaccharides may be the neutrophil ligands involved in P-selectin-dependent adhesion $(17,18)$, although sulfated glycoproteins and glycolipids have also been identified provisionally as neutrophil "counter-receptors" for P-selectin (17). In general, ligands for P-selectin interact in a $\mathrm{Ca}^{2+}$ dependent manner with the $\mathrm{NH}_{2-}$ terminal lectin binding domain of P-selectin. It has been shown that the binding of $\mathrm{Ca}^{2+}$ to the lectin binding domain results in a conformational change in P-selectin, promoting ligand recognition $(19,20)$.

Previous studies in our laboratory have demonstrated that anti-P-selectin antibodies are protective in acute lung injury due to systemic complement activation after infusion of cobra venom factor into rats (21). Injury in this model reaches a peak within $30 \mathrm{~min}$, is dependent both on complement activation as

1. Abbreviations used in this paper: BCECF-AM, 2',7'-bis-(2-carboxyethyl)-5(and-6)-carboxyfluorescein, acetoxymethyl; C5aR, C5a receptor; HUVECs, human umbilical vein endothelial cells; ICAM-1 and -2 , intercellular adhesion molecules 1 and 2; ORF, open reading frame. 
well as on neutrophil-generated toxic oxygen products, and is associated with lung vascular expression of P-selectin. Antibody-induced blockade of P-selectin greatly reduces neutrophil accumulation in the lung and diminishes the intensity of injury (21). The following in vitro studies were designed to explore further the role of the anaphylatoxin peptide C5a on P-selectin expression and function in HUVECs. C5a has been found to cause in HUVECs a rapid increase in adhesion of unactivated neutrophils to the endothelial cells. This increased adhesiveness is mediated by C5a-induced P-selectin expression on the endothelium. Evidence is also provided for binding of C5a to endothelial cells and for the presence of mRNA for C5a receptor $(\mathrm{C} 5 \mathrm{aR})$ in these endothelial cells.

\section{Methods}

Chemicals and reagents. Recombinant human C5a was a gift of Dr. Henry Showell (Pfizer Central Research, Groton, CT). The $\mathrm{ED}_{50}$ for the chemotactic activity of this C5a preparation was $1-5 \mathrm{nM}$. This was based on four separate determinations, using polycarbonate membranes (polyvinyl chloride-free) with $3-\mu \mathrm{m}$ pores. Human blood neutrophil migration occurred over a 30-min period. Neutrophils were quantitated by fluoremetric analysis as recently described (22). cDNA for human neutrophil C5aR was the gift of Drs. Craig and Norma Gerard (Children's Hospital, Boston, MA). Murine monoclonal antibodies against human P-selectin (PNB1.6 and PB1.3) were the gift of Dr. James C. Paulson (Cytel Corporation, San Diego, CA). Monoclonal antibody to human CD18 was provided by Dr. C. Wayne Smith (Baylor University, Houston, TX). The human anti-E-selectin monoclonal antibody (CL3) has been described previously (23). Anti-ICAM-1 antibody was obtained from Research and Diagnostic Systems (Minneapolis, MN). Antibodies to human Fc $\gamma$ RII (IV.3) and Fc $\gamma$ RIII (3G8) were purchased from Medarex, Inc. (West Lebanon, NH), while TNF- $\alpha$ was obtained from Peprotech (Rocky Hill, NJ). The 2',7'-bis-(2-carboxyethyl)5(and-6)-carboxyfluorescein, acetoxymethyl (BCECF-AM) used for fluorescent labeling of neutrophils was purchased from Molecular Probes (Eugene, OR). Silicone oil (SF1250; General Electric) was the gift of Scot Westerbeek (Matteson-Ridolfi Incorporated, Riverview, MI). Radioiodinated C5a was purchased from NEN-Dupont (Wilmington, DE). Other reagents were obtained from Sigma Chemical Co. (St. Louis, MO).

Endothelial cell preparation. HUVECs were isolated by collagenase treatment of freshly obtained human umbilical cords and plated on gelatin-coated tissue culture dishes (Falcon Co., Lincoln Park, NJ) (24). Dulbecco's modified Eagle's media with Ham's F-12 and 20\% heatinactivated fetal bovine serum (FBS) supplemented with $2 \mathrm{mM}$ L-glutamine, $100 \mathrm{U} / \mathrm{ml}$ penicillin, $100 \mu \mathrm{g} / \mathrm{ml}$ streptomycin, $0.25 \mu \mathrm{g} / \mathrm{ml}$ Fungizone, $25 \mu \mathrm{g} / \mathrm{ml}$ endothelial cell growth supplement (Collaborative Research, Bedford, MA), and $15 \mathrm{U} / \mathrm{ml}$ bovine heparin was used to maintain the cells. HUVECs were used between the first and third passage and were characterized by a cobblestone appearance and specific staining for von Willebrand factor ( $\mathrm{vWf})$.

Preparation of neutrophils. Whole blood was obtained from healthy human volunteers and anticoagulated with citrate dextrose solution. Neutrophils were isolated by gradient centrifugation over Ficoll-Hypaque (Pharmacia, Uppsala, Sweden) followed by $1 \%$ dextran sedimentation for $1 \mathrm{~h}$ to separate neutrophils from erythrocytes. Remaining erythrocytes were removed by hypotonic lysis and the neutrophils were washed twice in Hanks' balanced salt solution containing $0.1 \%$ bovine serum albumin (HBSS-BSA). Cells were resuspended to $5 \times 10^{6}$ cells/ $\mathrm{ml}$ in HBSS-BSA, and preparations contained $>95 \%$ neutrophils.

Fluorescent labeling of neutrophils. 50- $\mu \mathrm{g}$ aliquots of BCECF-AM were freshly dissolved in $50 \mu$ l dimethylsulfoxide. This was then added to the neutrophil suspension at a final concentration of $1 \mathrm{mM} \mathrm{BCECF-}$ AM. The mixture was incubated for $30 \mathrm{~min}$ at $37^{\circ} \mathrm{C}$, and then the cells were washed twice with $4^{\circ} \mathrm{C}$ HBSS-BSA. The cells were then resuspended in HUVEC media at $1 \times 10^{6}$ cells $/ \mathrm{ml}$ for use in the adhesion assay.

Assay of neutrophil adherence to HUVEC monolayers. An assay for measuring static adhesion of fluorescent-labeled neutrophils to HUVEC monolayers has been recently described (25). Briefly, HUVECs were plated at $5 \times 10^{4}$ cells/well in 96-well flat-bottom fibronectin-coated plates and grown to confluence at $37^{\circ} \mathrm{C}$ with $5 \% \mathrm{CO}_{2}$. The cells were washed twice with fresh HUVEC media. Recombinant C5a or TNF- $\alpha$ was added to the appropriate wells (as indicated) and incubated at $37^{\circ} \mathrm{C}$ with $5 \% \mathrm{CO}_{2}$. The cells were then washed twice with warm media and $1 \times 10^{5}$ fluorescent-labeled neutrophils were added to each well. A standard curve relating cell number to fluorescence was prepared on each plate by performing twofold serial dilutions of the neutrophils from $1 \times 10^{5}$ to $6.25 \times 10^{3}$ cells $/$ well. Microtiter plates were incubated for $30 \mathrm{~min}$ at $37^{\circ} \mathrm{C}$ with $5 \% \mathrm{CO}_{2}$. The nonadherent neutrophils were then removed with gentle washing. Remaining fluorescence was measured with a fluorescence measurement system (Cytofluor model 2300; Millipore, Bedford, MA) using an excitation filter at $485 \mathrm{~nm}$ and emission filter at $530 \mathrm{~nm}$. In experiments using monoclonal antibodies to block neutrophil binding, antibodies $(10-20 \mu \mathrm{g} / \mathrm{ml})$ were added to the wells containing the neutrophils. All antibodies were used as intact murine $\mathrm{IgG}_{1}$ monoclonal antibodies. Fluorescent-labeled neutrophils were treated for $15 \mathrm{~min}$ at room temperature with $10 \mu \mathrm{g} / \mathrm{ml}$ antibodies to block Fc receptor interactions immediately before their addition to microtiter wells

ELISA for adhesion molecule expression. An ELISA to determine adhesion molecule expression on monolayers of endothelial cells was developed in this laboratory (26). Briefly, HUVECs were plated at 5 $\times 10^{4}$ cells/well in 96-well flat-bottom fibronectin-coated plates and grown to confluence at $37^{\circ} \mathrm{C}$ with $5 \% \mathrm{CO}_{2}$. The cells were washed with warm HUVEC media and stimulated as described in the text at $37^{\circ} \mathrm{C}$. After stimulation, the endothelial cell monolayers were washed and fixed with $1 \%$ paraformaldehyde. $5 \%$ nonfat dry milk was used to reduce nonspecific binding and the cells incubated with primary antibody ( 1 $\mu \mathrm{g} / \mathrm{ml}$ ) for $45 \mathrm{~min}$. The cells were washed and a peroxidase-conjugated rabbit anti-mouse IgG (Dako Corporation, Carpinteria, CA) was added for $40 \mathrm{~min}$. After washing, the substrate (o-phenylenediamine dihydrochloride) was added for $30 \mathrm{~min}$ and the reaction was quenched with 3 M sulfuric acid. Optical density was determined at $490 \mathrm{~nm}$ using an automated microplate reader (EL340; Bio-Tek Instruments, Winooski, VT).

Preparation of C5a des arg. $100 \mu \mathrm{l}$ of a $10 \mu \mathrm{M}$ stock solution of $\mathrm{C} 5 \mathrm{a}$ was incubated for $30 \mathrm{~min}$ at $37^{\circ} \mathrm{C}$ with $5 \mathrm{U}$ carboxypeptidase B. The carboxypeptidase $\mathrm{B}$ was then heat inactivated by incubating the mixture for $30 \mathrm{~min}$ at $56^{\circ} \mathrm{C}$.

ELISA for $v W f$. HUVECs were grown to confluence in a $150-\mathrm{mm}$ gelatin-coated tissue culture dish. The cells were washed twice with Dulbecco's modified Eagle's media and incubated for $15 \mathrm{~min}$ with indicated inflammatory mediators. Supernatants were collected, filter sterilized to remove any contaminating HUVECs, and concentrated to $1 \mathrm{ml}$. Twofold serial dilutions of the supernatants were incubated for $2.5 \mathrm{~h}$ in wells of a 96-well plate coated with anti-human vWf and blocked with BSA. A standard curve of $\mathrm{vWf}$ concentration was prepared on each plate by performing twofold serial dilutions of human reference plasma from 2,500 to $2.4 \mathrm{pg}$ vWf. The plates were washed and a peroxidase-conjugated rabbit anti-human vWf was added for $2 \mathrm{~h}$. After washing, the substrate (o-phenylenediamine dihydrochloride) was added for $10 \mathrm{~min}$ and the reaction was quenched with $3 \mathrm{M}$ sulfuric acid. Optical density was determined at $490 \mathrm{~nm}$ using an automated microplate reader.

C5a binding studies. Binding of C5a to neutrophils and HUVECs was performed using a silicone oil technique similar to that described previously (27). Briefly, HUVECs were removed from tissue culture dishes using $0.02 \%$ EDTA and washed twice in binding buffer $(50 \mathrm{mM}$ Hepes, pH 7.4, containing $1 \mathrm{mM} \mathrm{CaCl}_{2}, 5 \mathrm{mM} \mathrm{MgCl}_{2}, 0.5 \%$ BSA, 10 $\mathrm{mM}$ glucose, $0.1 \%$ bacitracin, $1 \mathrm{mg} / \mathrm{ml}$ leupeptin, and $2 \mu \mathrm{g} / \mathrm{ml}$ aprotinin) $(28) .2 \times 10^{6}$ cells were incubated for $60 \mathrm{~min}$ on ice with $10 \mathrm{nM}$ C5a supplemented with $0.1 \mathrm{nM}$ radioiodinated C5a $(\sim 60,000 \mathrm{cpm})$ in a final volume of $300 \mu \mathrm{l} .100-\mu \mathrm{l}$ aliquots of the cell suspension were 
layered on $200 \mu \mathrm{l}$ of silicone oil in a $400-\mu \mathrm{l}$ polyethylene microcentrifuge tube and centrifuged for $2 \mathrm{~min}$ in a microfuge (Beckman Instruments, Inc., Fullerton, CA). Near the pellets, the tubes were transected with a razor blade separating the pellet containing cell-associated radioiodinated C5a from unbound C5a in the supernatant fluid. Cell-associated and free radioactivity were measured in a gamma counter and molecules of C5a bound per cell were calculated. C5a binding to neutrophils was measured in a manner similar to that used for HUVECs, with the exception that $5 \times 10^{6}$ neutrophils were used in the assay. Nonspecific binding to both cell types was measured in the presence of 1,000 fold excess unlabeled C5a (29).

Detection of mRNA for the C5a receptor. Total RNA was isolated using Trizol Reagent (Gibco, Gaithersburg, MD) using $\sim 1 \times 10^{7}$ HUVECs (30). mRNA from the HUVECs was subject to reverse transcription using a cDNA cycle kit (Invitrogen, San Diego, CA) with oligo dTs as a primer. Single-stranded cDNA was then amplified over 35 cycles using PCR with primers directed against the full open reading frame ( 1,053 bases) or a fragment of the open reading frame (636 bases) of the oligonucleotide coding for the neutrophil C5a receptor. cDNA from the neutrophil C5a receptor was used as a positive control for the C5a receptor primers. PCR products were analyzed on a $0.9 \%$ agarose gel and the bands were visualized with ethidium bromide.

Statistical analysis. Each ELISA and cell adhesion assay experiment contained four to six replicates and was repeated three times with similar results. Data from separate experiments were not merged because of intrinsic differences in the optical density values from experiment to experiment, reflective of baseline immunoperoxidase products. In contrast, cell adhesion studies between experiments were highly reproducible relative to values of nonstimulated and stimulated HUVECs. For brevity and clarity, we have routinely presented data from individual experiments. For each data point, values (mean $\pm S E M$ ) represent results from replicates (4-6). Where the error bars are not visible in the figures, this is due to the very small value of the error bar. Where not displayed, SEM values are described in the figure legends. The C5a binding experiments were performed in triplicate and in nine independent experiments. Each data point represents the mean from a representative experiment \pm SEM. Statistical differences between groups were measured by analysis of variance.

\section{Results}

Histamine-induced P-selectin expression on HUVECs and increased neutrophil adhesion. HUVEC monolayers were stimulated with increasing concentrations of histamine for $5 \mathrm{~min}$, followed by immediate washing, fixation, and determination of P-selectin expression with a cell-based ELISA. As shown by the data in Fig. $1 A$, a dose-dependent increase in P-selectin expression occurred after stimulation with histamine. To determine neutrophil adhesion, HUVEC monolayers were incubated for $5 \mathrm{~min}$ with increasing concentrations of histamine, followed by washing and addition of neutrophils. Concentrations of histamine of $\leq 0.1 \mathrm{mM}$ did not promote neutrophil adhesion (Fig. $1 B$ ). Incubation of the endothelial cells with concentrations of histamine of $\geq 500 \mu \mathrm{M}$ resulted in significant increases in neutrophil adherence, with a plateau in cell adhesion appearing between 1 and $5 \mathrm{mM}$ concentrations of histamine. Upregulation of P-selectin expression after exposure of endothelial cells to 5 $\mathrm{mM}$ histamine was rapid, reaching a peak within $5 \mathrm{~min}$, with a return toward basal levels by $30 \mathrm{~min}$ (Fig. 2). Similar results have been previously reported using a direct immunochemical detection ( ${ }^{125} \mathrm{I}$-antibody) of P-selectin expression on histaminestimulated endothelial cells (11).

Thrombin-induced P-selectin expression on HUVECs. As expected, incubation of HUVECs with increasing concentrations of thrombin for $5 \mathrm{~min}$ resulted in a dose-dependent in-
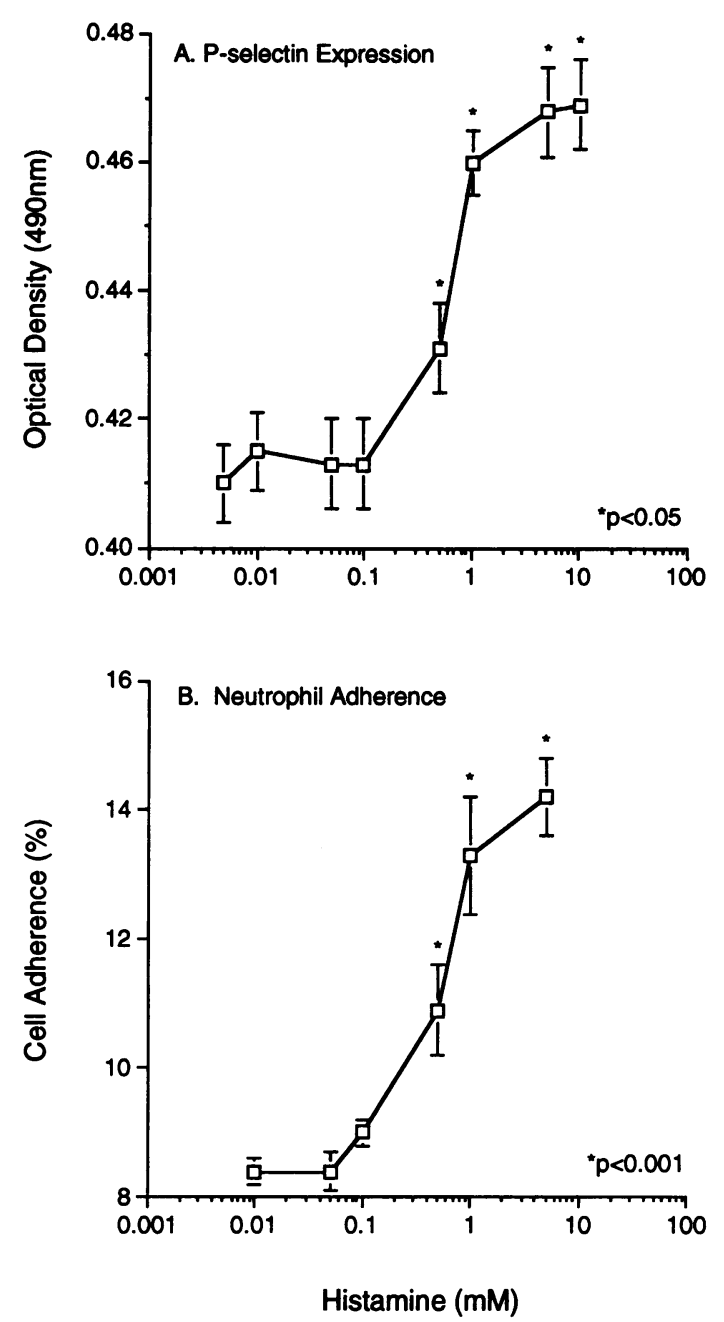

Figure 1. Dose-responses for histamine stimulation of HUVEC monolayers. Cells were incubated with increasing concentrations of histamine for 5 min followed by washing. $(A)$ Endothelial cell P-selectin expression was measured by an ELISA. (B) Human blood neutrophils were added and adhesion evaluated $30 \mathrm{~min}$ later. All comparisons were to non-histamine-exposed HUVECs.

crease in P-selectin expression (Fig. 3). Concentrations of thrombin of $\geq 0.1 \mathrm{U} / \mathrm{ml}$ resulted in significant upregulation of P-selectin on HUVECs, with a plateau between 1 and $10 \mathrm{U}$ thrombin/ml. Again, these results are similar to those in which a different immunochemical analysis has been employed (11).

C5a-induced P-selectin expression on HUVECs and increased neutrophil adhesion. HUVEC monolayers were incubated with increasing concentrations of C5a for $10 \mathrm{~min}$, followed by washing and evaluation of P-selectin expression. C5a promoted a dose-dependent increase in P-selectin expression on HUVECs (Fig. $4 A$ ). C5a concentrations of $\leq 25 \mathrm{nM}$ did not result in increased expression, while $\mathrm{C} 5$ a concentrations of $\geq 50$ $\mathrm{nM}$ resulted in significant upregulation of $\mathrm{P}$-selectin $(P$ $<0.05)$. When $250 \mathrm{nM}$ C5a des arg was used, the increase in P-selectin was abolished (Fig. $4 \mathrm{~A}$ ) as was the increased cell adhesion (Fig. $4 B$ ). The dose response profile with neutrophil adhesion showed a similar profile (Fig. $4 B$ ). The relatively high concentrations of $\mathrm{C} 5 \mathrm{a}$ required to induce endothelial cell responsiveness was not due to poor activity of the C5a prepara- 


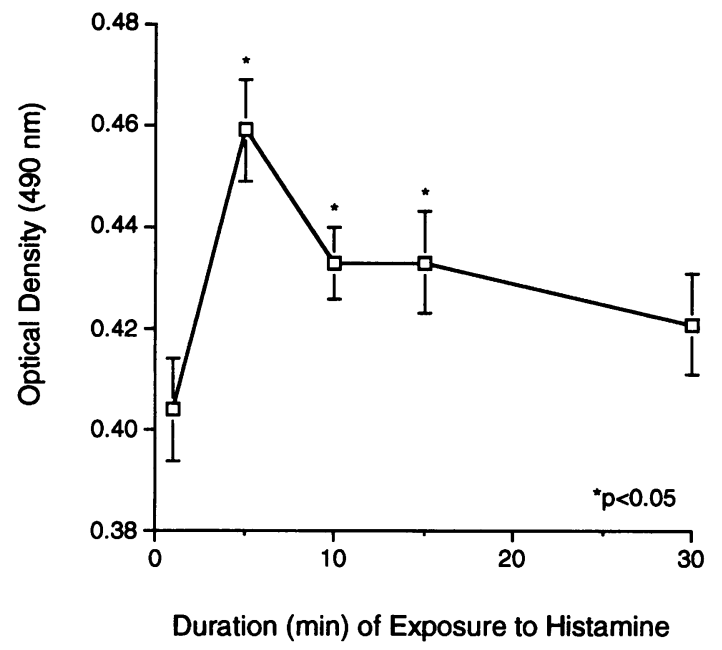

Figure 2. Upregulation of endothelial cell P-selectin expression after incubation with $5 \mathrm{mM}$ histamine for 1-30 min. P-selectin expression was measured by an ELISA method. All comparisons were to nonhistamine-exposed HUVECs.

tion, because the same preparation of $\mathrm{C} 5 \mathrm{a}$ induced neutrophil chemotactic responsiveness in the range of 1-5 $\mathrm{nM}$ (see above). This activity is consistent with the biological activity of C5a purified from activated human serum (31). In companion studies in which endothelial cell monolayers were exposed to a range of concentrations of $\mathrm{C5a}$ for $10 \mathrm{~min}$ and then washed, neutrophil adhesion to C5a-stimulated HUVECs was increased by as much as 5.8 -fold, in comparison to unstimulated cells (18.6 \pm 1.0 vs. $3.2 \pm 0.3 \%)$.

Studies were performed to determine the time course for Pselectin expression as well as neutrophil adhesion to HUVECs. Endothelial cells were incubated with $250 \mathrm{nM}$ C5a for 2, 5, 10, 15 , or $30 \mathrm{~min}$, followed by washing. As shown in Fig. $5 \mathrm{~A}$, P-selectin expression was upregulated rapidly, demonstrating

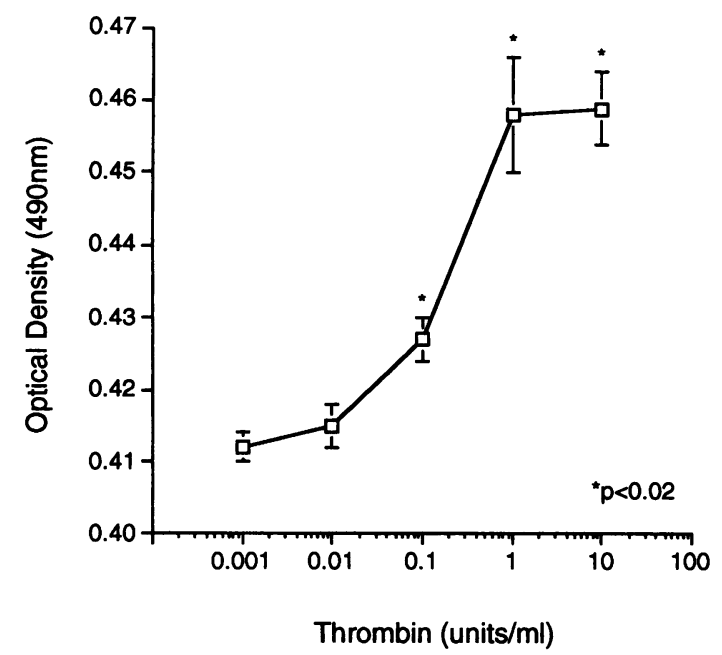

Figure 3. Dose-responses for thrombin stimulation of HUVEC monolayers. Cells were incubated with increasing concentration of thrombin for 5 min followed by washing. P-selectin expression was measured by an ELISA method. Comparisons were to non-thrombin-exposed HUVECs.
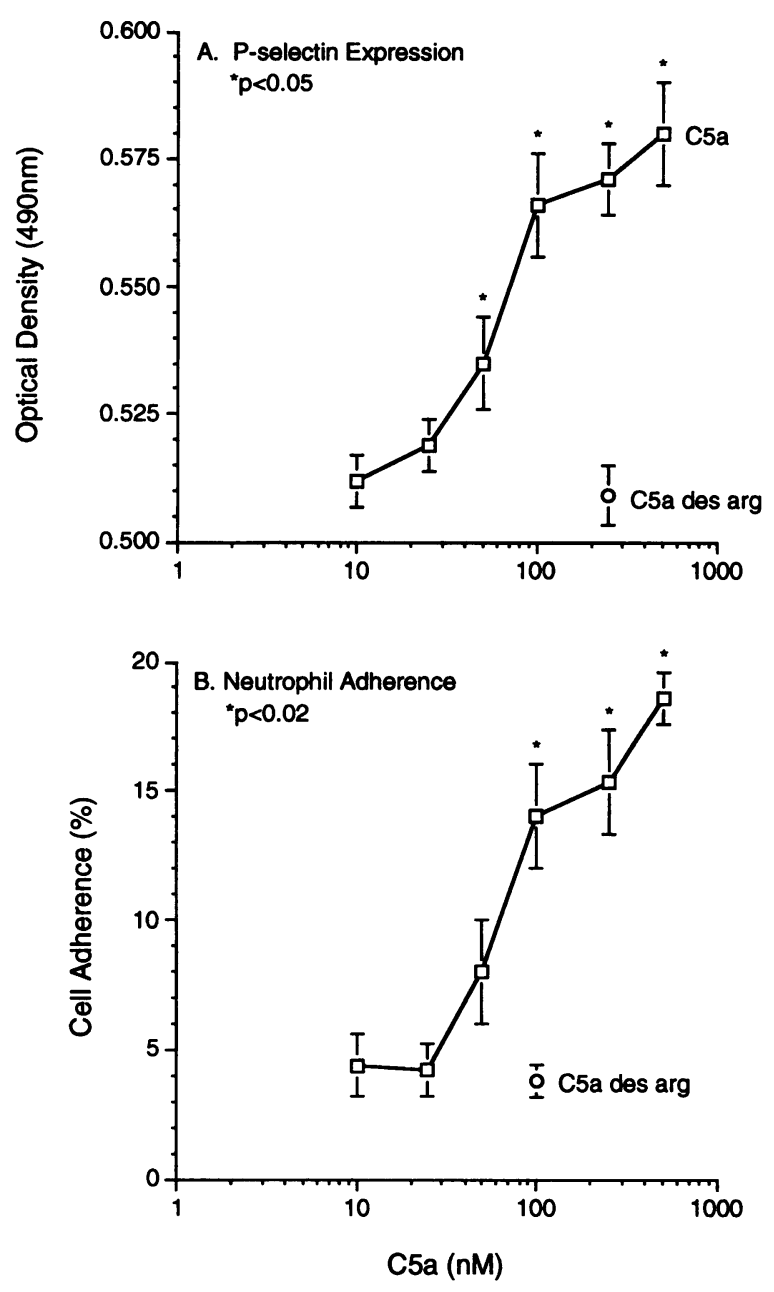

Figure 4. Dose-responses for C5a stimulation of HUVEC monolayers. Cells were incubated with increasing concentrations of C5a for $10 \mathrm{~min}$ followed by washing. $(A)$ Endothelial cell P-selectin expression was measured by an ELISA method. $(B)$ Neutrophils were added and adhesion evaluated $30 \mathrm{~min}$ later. Neutrophil adhesion to unstimulated HUVECs was $3.2 \pm 0.3 \%$. For both P-selectin and neutrophil adhesion measurements, C5a des arg showed no activity. All comparisons were to non-C5a-treated HUVECs.

increased expression $(P<0.001)$ over basal levels after $5-$, 10-, and 15-min exposure to $\mathrm{C5a}$, with a return to baseline by $30 \mathrm{~min}$. These data demonstrate that $\mathrm{C} 5 \mathrm{a}$, like histamine, can rapidly upregulate P-selectin expression on endothelial cells. A similar time course was observed for neutrophil adhesion to HUVECs incubated with $250 \mathrm{nM}$ C5a for various periods of time. Rapid and significant increases $(P<0.01)$ in neutrophil adhesion were demonstrated with HUVECs incubated with C5a for 5,10 , and $15 \mathrm{~min}$ (Fig. $5 \mathrm{~B}$ ). HUVECs exposed for $30 \mathrm{~min}$ to C5a also bound significantly more neutrophils than unstimulated HUVECs, although at this time point, neutrophil adhesion was returning toward baseline levels.

Stabilization of P-selectin expression on HUVECs by removal of C5a. After stimulation of endothelial cell monolayers, the neutrophil adhesion assay is associated with a 30-min incubation during which the neutrophils settle onto and interact with the endothelial cells. Experiments were designed to determine if continuous presence of $\mathrm{C5a}$ would affect P-selectin expres- 

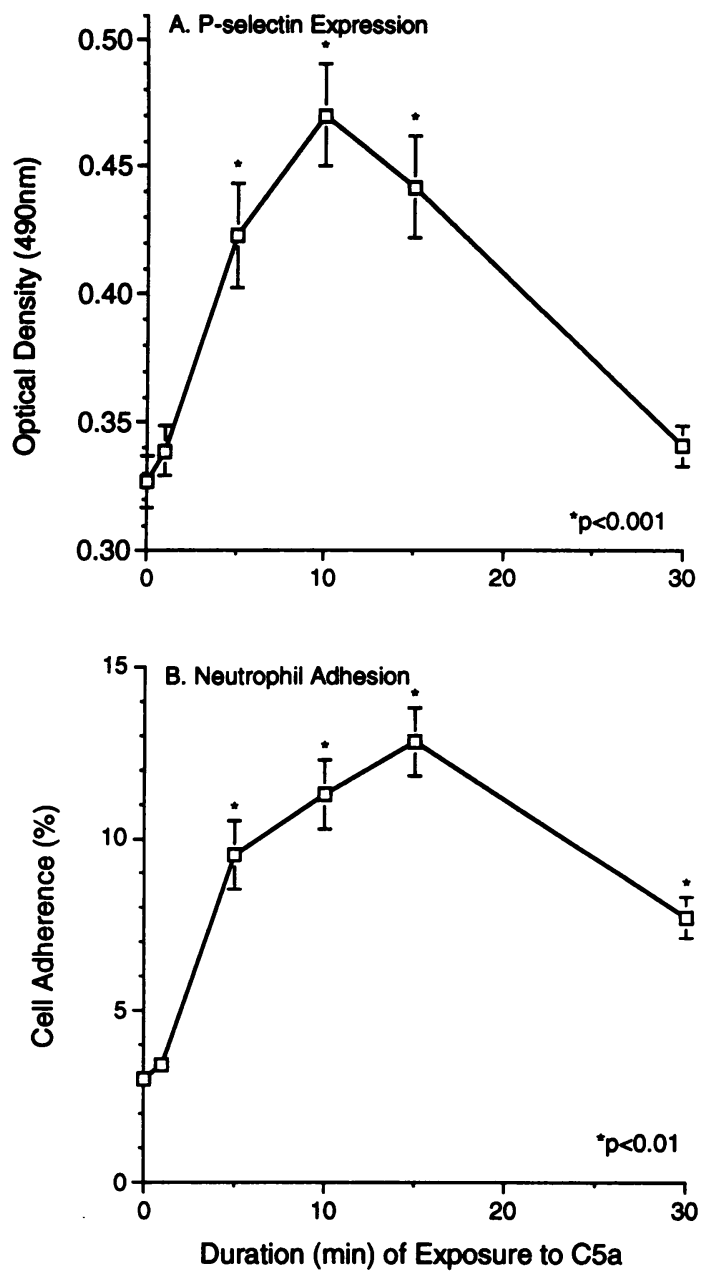

Figure 5. Time course for C5a-mediated P-selectin expression and neutrophil adhesion to HUVEC monolayers. Endothelial cells were incubated with $250 \mathrm{nM}$ C5a for 0-30 min followed by washing. (A) Pselectin expression on HUVECs was measured with an ELISA method. $(B)$ Neutrophils were added and adhesion measured $30 \mathrm{~min}$ later. Error bars in $A$ for the first two points were 0.20 and 0.10 , respectively. All comparisons were to the time 0 values.

sion on endothelial cells. It should be noted that in the adhesion assay endothelial cells were incubated with C5a for a given period of time, following which C5a was removed by washing the monolayers before addition of neutrophils. Accordingly, for these experiments endothelial cell monolayers were treated with $250 \mathrm{nM} \mathrm{C5a}$ and then washed after 10 or $30 \mathrm{~min}$. Monolayers were fixed, as indicated, by addition of paraformaldehyde (as described above) and P-selectin expression was evaluated by the ELISA assay. The results are shown in Fig. 6, where it is evident that increased P-selectin expression was similar, provided the monolayers were washed $10 \mathrm{~min}$ after addition of C5a and regardless of time of fixation. In sharp contrast, the continuing presence of $\mathrm{C5a}$ for $\mathbf{3 0} \mathrm{min}$ resulted in a significant $(P<0.03)$ loss in increased expression of P-selectin. Reasons for the differences in stability of P-selectin expression are not known. These data suggest that continued presence of C5a may result in loss of $\mathrm{P}$-selectin. In view of these data, in all subsequent experiments, unless otherwise indicated, endothelial cell activation with $250 \mathrm{nM}$ C5a occurred for a 10-min period followed by washing.
C5a-induced $v W f$ secretion from HUVECs. Confluent HUVECs were incubated for $15 \mathrm{~min}$ with a range of concentrations of C5a, histamine, thrombin, or media (as a negative control), and the supernatant fluids were then evaluated by ELISA for secreted vWf. Incubation of HUVECs with C5a $(10,100$, and $250 \mathrm{nM}$ ) induced $\mathrm{vWf}$ secretion that increased significantly compared with that released from unstimulated HUVECs (Fig. 7). Stimulation of HUVECs with histamine ( 1 and $5 \mathrm{mM}$ ) or thrombin $(10 \mathrm{U} / \mathrm{ml})$ also resulted in increased $\mathrm{vWf}$ release, a finding that has been described previously (11).

$P$-selectin dependency of neutrophil adherence to C5a-stimulated HUVECs. HUVEC monolayers were incubated with 250 $\mathrm{nM} \mathrm{C5a}$ for $10 \mathrm{~min}$, followed by washing and addition of neutrophils. Antibodies were added to the HUVEC monolayers, at a final concentration of $20 \mu \mathrm{g} / \mathrm{ml}$, followed by addition of neutrophils (which had been pretreated with blocking antibodies to Fc $\gamma$ RII and Fc $\gamma$ RIII). Under these conditions, anti-P-selectin antibody reduced neutrophil adhesion by $59 \%(P<0.001)$, while antibodies to E-selectin, ICAM-1, and CD18, as well as a combination of these antibodies (at $20 \mu \mathrm{g} / \mathrm{ml}$ each) did not affect neutrophil binding to the HUVECs (Fig. $8 \mathrm{~A}$ ). To demonstrate the blocking capabilities of the antibodies to E-selectin, ICAM-1, and CD18, neutrophil adhesion was evaluated in HUVECs stimulated with $25 \mathrm{ng} / \mathrm{ml} \mathrm{TNF}-\alpha$ for $2 \mathrm{~h}$ (in the presence of $10 \mu \mathrm{g} / \mathrm{ml}$ of these antibodies ). Anti-E-selectin, anti-ICAM1 , and anti-CD18 antibodies all decreased significantly neutrophil binding $(P<0.001)$ to TNF- $\alpha$-stimulated HUVECs, with a combination of these antibodies reducing neutrophil adhesion by $32 \%(P<0.001)$ (Fig. $8 \mathrm{~B})$. These results are similar to those reported previously (25). In contrast, anti-P-selectin did not affect neutrophil adhesion to TNF- $\alpha$-stimulated HUVECs (Fig. $8 \mathrm{~B}$ ).

Lack of expression of E-selectin in C5a-stimulated $\mathrm{HU}$ $V E C s$. HUVECs were stimulated with $25 \mathrm{ng} / \mathrm{ml}$ TNF- $\alpha, 250$ $\mathrm{nM} \mathrm{C5a}$, or $5 \mathrm{mM}$ histamine for $2,5,10,15,30$, or $120 \mathrm{~min}$, washed, and immediately evaluated for E-selectin expression. As expected, incubation of endothelial cells with TNF- $\alpha$ for $2 \mathrm{~h}$ resulted in a significant increase in E-selectin expression compared with baseline values (optical density of $1.731 \pm 0.02$ vs. $0.669 \pm 0.012, P<0.001$ ) (data not shown). In contrast, incubation of HUVECs with C5a or histamine did not promote E-selectin upregulation at $4 \mathrm{~h}$ (data not shown). Thus, C5a stimulation of HUVECs results in upregulation of P-selectin, but not E-selectin.

Binding of C5a to HUVECs. $2 \times 10^{6}$ HUVECs were incubated for $60 \mathrm{~min}$ on ice with $10 \mathrm{nM}$ C5a supplemented with $0.1 \mathrm{nM}$ radioiodinated $\mathrm{C5a}(\sim 60,000 \mathrm{cpm})$. Aliquots of the cell suspension were layered on silicone oil and centrifuged to separate bound and free radioligand. The results revealed an average of $4,940 \pm 360$ molecules of C5a bound per cell. The cells bound $\sim 3 \%$ of the total radioligand added; $\sim 40-50 \%$ of this amount of C5a failed to bind in the presence of 1,000 fold excess unlabeled C5a. Binding of the same radioiodinated C5a to neutrophils revealed $\sim 70,000$ C5a molecules per cell (data not shown). These findings were characteristic of results obtained in nine separate experiments. Because of technical problems it has not been possible to obtain data sufficient for Scatchard analysis and computation of binding affinities. These data suggest that C5a binds to endothelial cells, but the data are insufficient to prove receptor-mediated binding.

Detection in endothelial cells of $m R N A$ for $C 5$ a receptor. cDNA was prepared from HUVEC mRNA using reverse tran- 


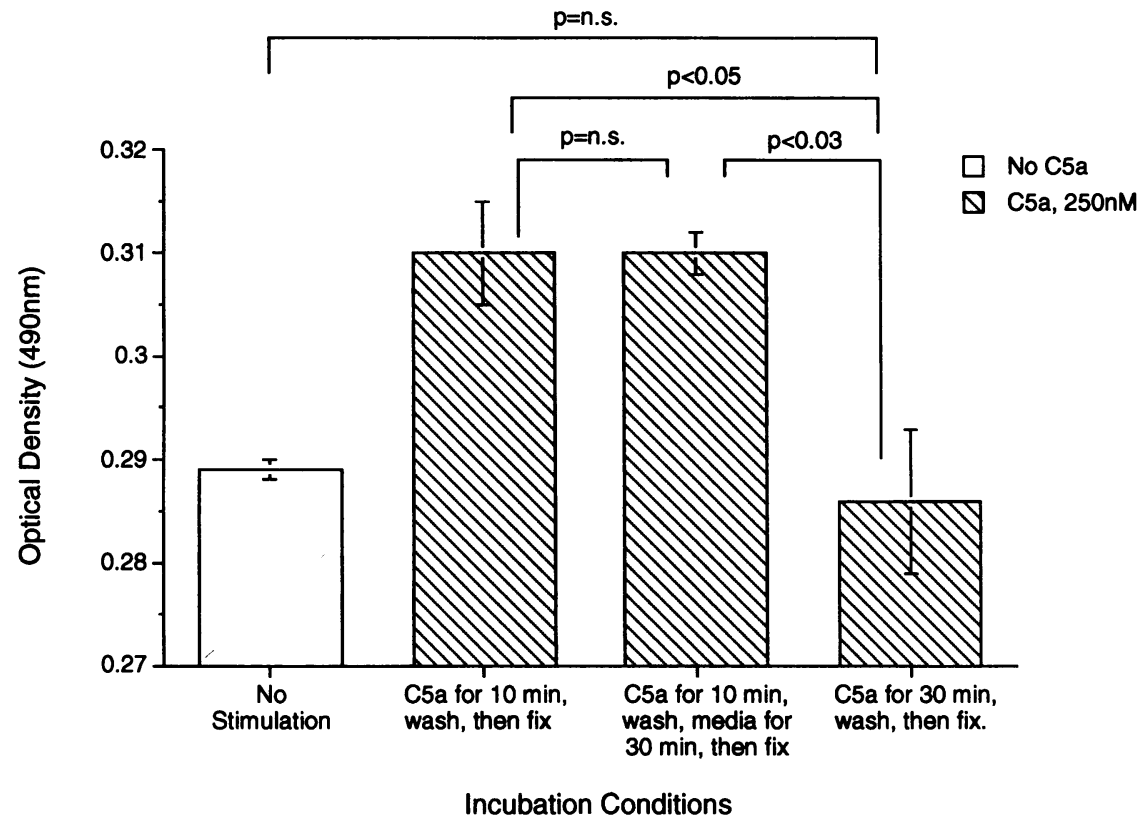

Figure 6. Stabilization of P-selectin expression on HUVECs. Endothelial cells were incubated with $250 \mathrm{nM} \mathrm{C5a}$ for 10 or $30 \mathrm{~min}$, followed by washing (and fixation with $1 \%$ paraformaldehyde, as indicated) and an additional $30 \mathrm{~min}$ incubation in media. P-selectin expression was assayed with the ELISA method. scriptase. The cDNA was then amplified using PCR with primers directed against either the full open reading frame (full ORF, 1,053 bases) or a fragment of the open reading frame (partial ORF, 636 bases) for the neutrophil C5aR. A positive control of cDNA for the neutrophil C5aR was used for PCR, and a single band at $\sim 1,000$ bases was visualized using the full ORF primers, while a band at $\sim 600$ bases was seen with the partial ORF primers (Fig. 9, $A$ and $B$, lane 2 ). PCR products from unstimulated HUVECs as well as TNF- $\alpha-$ or IFN- $\gamma-$ stimulated cells each showed a band similar to neutrophil C5a receptor control at $\sim 1,000$ bases using the full ORF primers and $\sim 600$ bases using the partial ORF primers (Fig. 9, $A$ and $B$, lanes 3-5). Thus, TNF- $\alpha$ and IL-1 had no obvious effects on HUVEC content of mRNA for C5aR. Identical results were found using either passage one or passage three HUVECs (data not shown).

\section{Discussion}

Recently published data have indicated that C5a will cause endothelial cells (human umbilical vein or rat pulmonary artery endothelial cells) to activate protein kinase $\mathrm{C}$ and generate $\mathrm{D}$ myo-inositol 1,4,5-triphosphate, to produce $\mathrm{O}_{2}^{-}$and to convert xanthine dehydrogenase to xanthine oxidase $(32,33)$. The data in the current report indicate that $\mathrm{C5a}$ also will cause rapid expression of P-selectin and adherence of neutrophils. It is also evident from this report that C5a causes another feature of endothelial cell activation: secretion of $\mathrm{vWf}$ (occurring within $15 \mathrm{~min}$ ). Based on the use of blocking antibodies, the adhesionpromoting process induced by endothelial cell activation with $\mathrm{C} 5 \mathrm{a}$ has been shown to be P-selectin dependent. The failure of antibodies to ICAM-1 and CD18 to block this adhesion process (but to block TNF- $\alpha$-induced adhesiveness for neutrophils) sug-

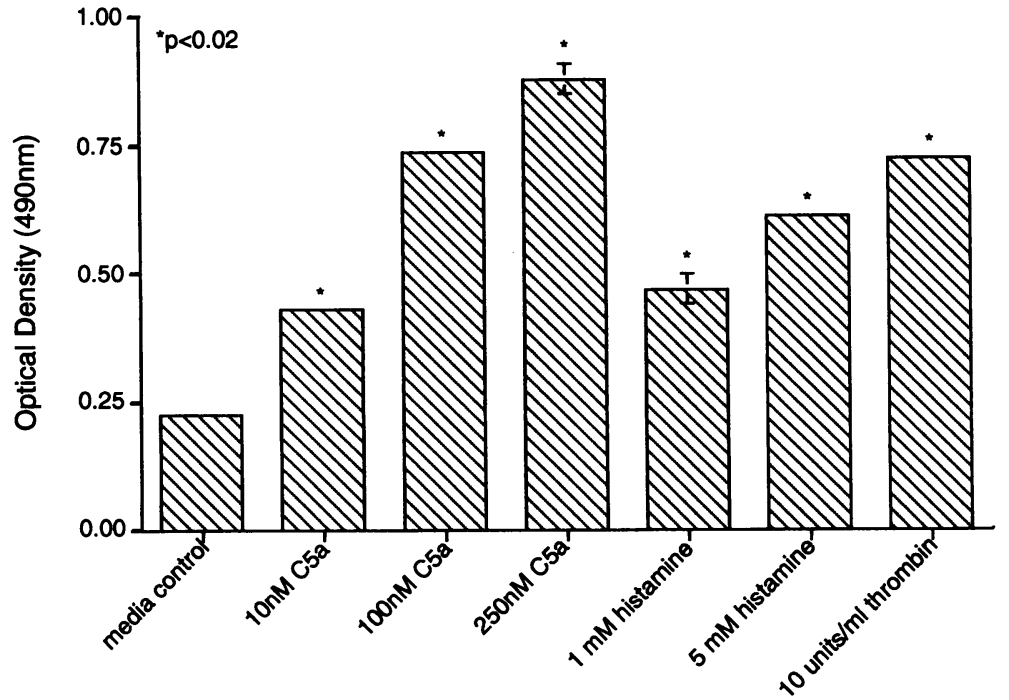

1152
Figure 7. Release of vWf from HUVEC monolayers. Cells were stimulated for $15 \mathrm{~min}$ with various inflammatory mediators and released vWf factor in the supernatant was measured with an ELISA method. *Statistically significant difference $(P<0.05)$ with respect to the media control. Where not displayed, error bars were $<0.003$. 

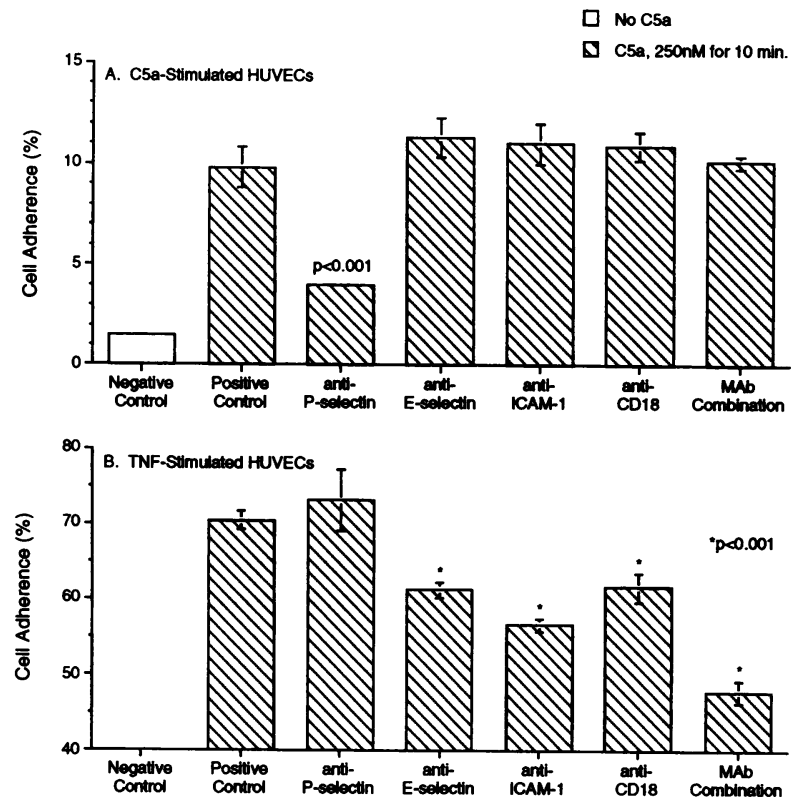

Figure 8. Monoclonal antibody blockade of neutrophil adherence to C5a-stimulated HUVEC monolayers $(A)$ or TNF- $\alpha$ stimulated monolayers $(B)$. Endothelial cells were stimulated with $250 \mathrm{nM}$ C5a for 10 min followed by washing and fixation. Neutrophils suspended in media containing $20 \mu \mathrm{g} / \mathrm{ml}$ of blocking antibodies to P- or E-selectin, ICAM$1, \mathrm{CD} 18$, or a combination of antibodies (to E-selectin, ICAM-1, and $\mathrm{CD} 18$ ) was added to the monolayers and adhesion measured $30 \mathrm{~min}$ later. Error bars in $A$ for the first and third bars were 0.08 and 0.02 , respectively. Other endothelial monolayers were also stimulated with TNF- $\alpha(25 \mathrm{ng} / \mathrm{ml})$ for $2 \mathrm{~h}$ followed by washing. Neutrophils, suspended in media containing $20 \mu \mathrm{g} / \mathrm{ml}$ of blocking antibodies to P- or E-selectin, ICAM-1, CD18, or a combination of antibodies (to E-selectin, ICAM1 , and $\mathrm{CD} 18$ ) was added to the monolayers and adhesion measured 30 min later. Adherence of neutrophils to unstimulated HUVECs (negative control) in this experiment was $4.1 \%(B) . P$ values were determined by comparison to the positive control groups.

gests that the adhesion-promoting process can not be attributed to nonspecific binding of C5a to endothelial cells, followed by activation of neutrophils, with resultant upregulation of CD11b/CD18 and cell adherence via the ICAM-1-dependent pathway.

Binding studies with ${ }^{125} \mathrm{I}-\mathrm{C} 5 \mathrm{a}$ reveal specific binding, although the small number of binding sites ( $10 \%$ of the number found on human neutrophils) and problems with insufficient levels of specific radioactivity in the $\mathrm{C} 5$ a preparations makes it difficult to obtain data sufficient for Scatchard analysis and calculation of binding affinities. Nevertheless, specific binding of C5a to HUVECs has been consistently found in our studies. The ability to demonstrate by reverse transcriptase-PCR technology the presence of mRNA for the C5aR, using probes to the C5aR of human neutrophils, strengthens the case for the presence in HUVECs of C5aR. To date, we have determined the C5aR is not upregulated in HUVECs stimulated with TNF$\alpha$, IL- $1 \beta$, or IFN- $\gamma$ (data not shown).

In earlier studies, two complement-related products have been described as being able to facilitate adhesion of neutrophils to endothelial cells. "C5a fragments" (zymosan-activated serum or a fraction thereof) were described as having the ability to modify neutrophils to enhance adhesion with endothelial cells
(34-36). The products in these preparations would likely have been C5a des arg, which, in our hands, has diminished activity for endothelial cells but is chemotactically active for neutrophils via the C5a des arg-vitamin D-binding protein complex (37, 38 ). It is known that C5a des arg has $1 / 10$ to $1 / 20$ the chemotactic activity for human blood neutrophils compared with C5a (39). It is also known that monocytes respond chemotactically to C5a and C5a des arg in a quantitatively similar manner (40). On balance, it would appear that the loss of activity of C5a des arg for upregulation of endothelial P-selectin and for neutrophil adhesion of treated endothelial cell monolayers is consistent with the interpretation that C5a des arg is a poor agonist for endothelial cells when compared with C5a. It appears that assembly of C5b-C9 on the surface of the endothelial cell can result in P-selectin upregulation, although this also ultimately causes some cytotoxicity as measured by release of lactic dehydrogenase (13). The ability of complement activation products to cause rapid upregulation of endothelial P-selectin may explain the ability of neutrophils to adhere rapidly to endothelium

A

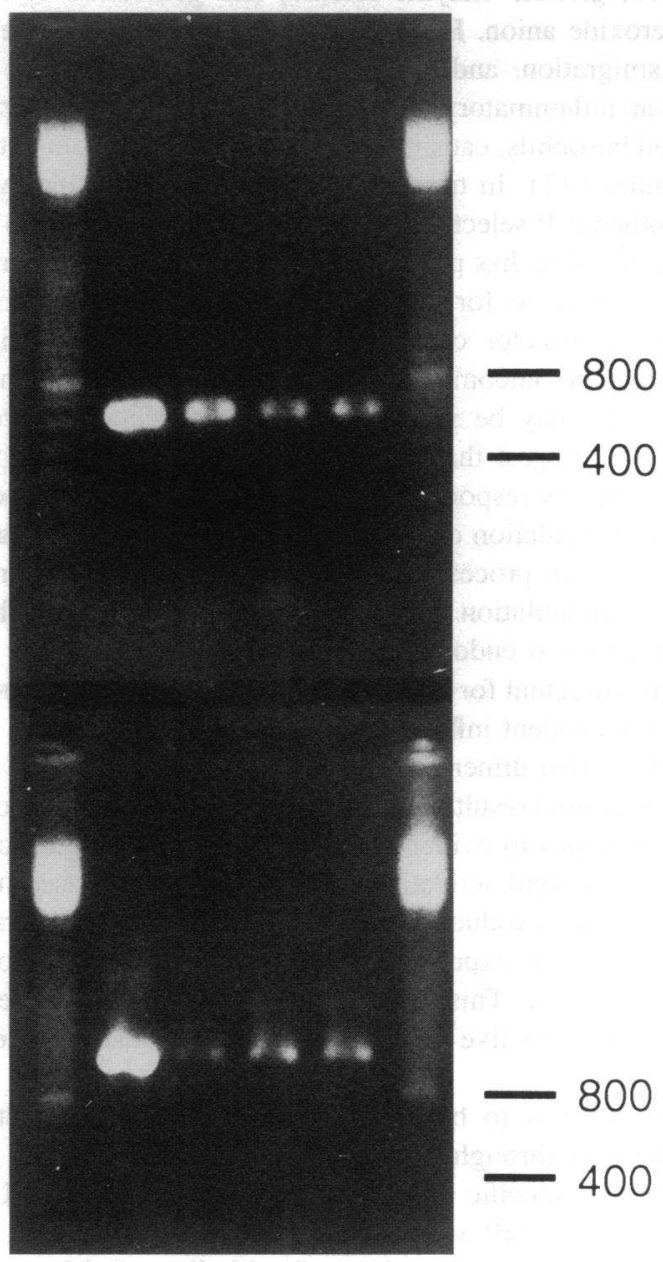

Figure 9. Detection of mRNA for C5a receptor in HUVECs. cDNA was prepared from total cellular RNA isolated from HUVECs. The cDNA was amplified using PCR with partial ORF primers $(A)$ or full ORF primers $(B)$, and the PCR product was evaluated on a $0.9 \%$ agarose gel. $A$ and $B$ : Lanes 1 and 6 , base pair ladder markers ( 100 and multiples thereof); lane 2, cDNA for C5aR obtained from HL-60 cells; lane 3, unstimulated HUVECs; lane 4, TNF- $\alpha$-stimulated HUVECs; lane 5 , IFN- $\gamma$ stimulated HUVECs. 
after injury, as opposed to the much slower onset of adhesion requiring upregulation of ICAM-1 and E-selectin. In preliminary experiments we have demonstrated that activation of whole human serum by cobra venom factor yields an activity that will cause upregulation of P-selectin on HUVEC (Foreman, K. E., and P. A. Ward, unpublished data). Whether this might be due to C5a des arg with its cofactor (vitamin D-binding protein [see above]), the membrane attack complex, or some other activation product remains to be determined.

Another pathway of rapid adhesion has been shown in vitro when $\mathrm{iC} 3 \mathrm{~b}$ is deposited on endothelial cells after the addition of fresh human serum to HUVECs that have been previously exposed to cobra venom factor conjugated to Ulex europaeus I. In this case, neutrophil adhesion to HUVECs peaks 10-15 min after addition of the complement source, and the adhesion is blocked by the presence of antibodies to CD11b or CD18 (41). The adhesion process has been attributed to CR3 (Mac1 or CD11b/CD18) on the neutrophil.

With respect to neutrophils, C5a binds to C5aR, inducing polarization, pseudopod formation, upregulation of CD11a/ CD18, granule enzyme release, and generation of $\mathrm{H}_{2} \mathrm{O}_{2}$ and superoxide anion. Each of these effects may enhance binding, transmigration, and effector function of neutrophils recruited into an inflammatory site. In addition, C5a can bind to peripheral blood basophils, causing release of histamine from cytoplasmic granules (42). In turn, this could also lead to upregulation of endothelial P-selectin. It can be surmised from these observations that C5a has potent agonist activities for both endothelial cells as well as for phagocytic cells and that the combination of these effector cell responses results in substantial proinflammatory outcomes. Obviously, determining which of these pathways may be involved in vivo is difficult. Nevertheless, the data suggest that C5a may play several roles in the acute inflammatory response. It may, as described in this report, cause rapid upregulation of $\mathrm{P}$-selectin, facilitating the earliest steps in the adhesion process; C5a can directly activate neutrophils to cause upregulation of $\mathrm{CD} 11 \mathrm{a} / \mathrm{CD} 18$, facilitating adhesion of neutrophils to endothelial ICAM-1; finally C5a may be a key chemoattractant for the transmigration of neutrophils in complement-dependent inflammation.

The other dimension in neutrophil adhesion to the activated endothelium (resulting in the ultimate transmigration of neutrophils) relates to evidence that, in the adhesion-promoting process, neutrophil activation (as assessed by increased intracellular $\mathrm{Ca}^{2+}$ and production of oxygen metabolites) occurs because of endothelial expression of platelet-activating factor and/or IL-8 $(43,44)$. This activation process may prime neutrophils for more effective transmigrational response to chemotactic factors.

It remains to be demonstrated that $\mathrm{C} 5 \mathrm{a}$ interaction with HUVEC is through a receptor-mediated mechanism. The evidence for specific binding and the detection in HUVEC of mRNA for C5aR support this possibility but do not prove it. The earlier lack of evidence for binding of C5a to HUVEC involved an entirely different binding assay for C5a (45). Our own experience has suggested that the technical approaches may affect C5a binding to HUVEC. For instance, neither suspensions of HUVEC nor monolayers have ever, in our hands, yielded evidence for specific binding of C5a (Foreman, K. E., and P. A. Ward, unpublished observations). It may be that technical problems have not been overcome entirely. In any case, definitive demonstration of C5aR-dependent binding of C5a to HUVEC remains to be demonstrated.

\section{Acknowledgments}

We thank Dr. David Ginsburg (University of Michigan Medical School) for performing the vWf ELISA. We thank Dr. Henry Showell (Pfizer Central Research, Groton, CT) for supplying recombinant human C5a, Drs. Craig and Norma Gerard (Children's Hospital, Boston, MA) for supplying cDNA for the human neutrophil C5aR, Dr. James C. Paulson (Cytel Corporation) for providing antibodies to human P-selectin, Dr. C. Wayne Smith (Baylor University) for providing antibody to human CD18, and Scot Westerbeek (Matteson-Ridolfi Incorporated) for the gift of General Electric silicone oil SF1250.

K. E. Foreman was funded by a fellowship from Parke-Davis Research Division of Warner-Lambert Company (Ann Arbor, MI). Other support was from National Institutes of Health grants HL-31963 and GM-29507.

\section{References}

1. Butcher, E. C. 1992. Leukocyte-endothelial cell adhesion as an active, multi-step process: a combinatorial mechanism for specificity and diversity in leukocyte targeting. In Mechanisms of Lymphocyte Activation and Immune Regulation IV: Cellular Communications. S. Gupta and T. A. Waldmann, editors. Plenum Press, New York. 181-194.

2. Paulson, J. C. 1992. Selectin/carbohydrate-mediated adhesion of leukocytes. In Adhesion. J. M. Harlan and D. Y. Lui, editors. W. H. Freeman and Company, New York. 19-42.

3. Lawrence, M. B., and T. A. Springer. 1991. Leukocytes roll on a selectin at physiologic flow rates: distinction from and prerequisite for adhesion through integrins. Cell. 65:859-873.

4. Muller, W. A., S. A. Weigl, X. Deng, and D. M. Philips. 1993. PECAM1 is required for transendothelial migration of leukocytes. J. Exp. Med. 178:449460.

5. Vaporciyan, A. A., H. M. DeLisser, H. Yan, I. I. Mendiguren, S. R. Thom, M. L. Jones, P. A. Ward, and S. M. Albelda. 1993. Involvement of plateletendothelial cell adhesion molecule-1 in neutrophil recruitment in vivo. Science (Wash. DC). 262:1580-1582.

6. Smith, C. W. 1992. Transendothelial migration. In Adhesion. J. M. Harlan and D. Y. Lui, editors. W. H. Freeman and Company, New York. 83-115.

7. McEver, R. P., and M. N. Martin. 1984. A monoclonal antibody to a membrane glycoprotein binds only to activated platelets. J. Biol. Chem. 259:9799-9804.

8. Stenberg, P. E., R. P. McEver, M. A. Shuman, Y. V. Jacques, and D. F. Bainton. 1985. A platelet alpha-granule membrane protein (GMP-140) is expressed on the plasma membrane after activation. J. Cell Biol. 101:880-886.

9. McEver, R. P., J. H. Beckstead, K. L. Moore, L. Marshall-Carlson, and D. F. Bainton. 1989. GMP-140, a platelet $\alpha$-granule membrane protein, is also synthesized by vascular endothelial cells and is localized in Weibel-Palade bodies. J. Clin. Invest. 84:92-99.

10. Bonfanti, R., B. C. Furie, B. Furie, and D. D. Wagner. 1989. PADGEM (GMP140) is a component of Weibel-Palade Bodies of human endothelial cells. Blood. 73:1109-1112.

11. Hattori, R., K. K. Hamilton, R. D. Fugate, R. P. McEver, and P. J. Sims. 1989. Stimulated secretion of endothelial von Willebrand factor is accompanied by rapid redistribution to the cell surface of the intracellular granule membrane protein GMP-140. J. Biol. Chem. 264:7768-7771.

12. Patel, K. D., G. A. Zimmerman, S. M. Prescott, R. P. McEver, and T. M. McIntyre. 1991. Oxygen radicals induce human endothelial cells to express GMP140 and bind neutrophils. J. Cell Biol. 112:749-759.

13. Hattori, R., K. K. Hamilton, R. P. McEver, and P. J. Sims. 1989. Complement proteins $\mathrm{C} 5 \mathrm{~b}-\mathrm{C} 9$ induce secretion of high molecular weight multimers of endothelial von Willebrand factor and translocation of granule membrane protein GMP-140 to the cell surface. J. Biol. Chem. 264:9053-9060.

14. Zimmerman, G. A., and T. M. McIntyre. 1988. Neutrophil adherence to human endothelium in vitro occurs by CDw18 (Mo-1, MAC-1/LFA-1/GP 150,95) glycoprotein-dependent and -independent mechanisms. J. Clin. Invest. 81:531-537.

15. Lorant, D. E., K. D. Patel, T. M. McIntyre, R. D. McEver, S. M. Prescott, and G. A. Zimmerman. 1991. Co-expression of GMP-140 and PAF by endothelium stimulated by histamine or thrombin: a juxtacrine system for adhesion and activation of neutrophils. J. Cell Biol. 115:223-234.

16. Geng, J., M. P. Bevilacqua, K. L. Moore, T. M. McIntyre, S. M. Prescott, J. M. Kim, G. A. Bliss, G. A. Zimmerman, and R. P. McEver. 1990. Rapid 
neutrophil adhesion to activated endothelium mediated by GMP-140. Nature (Lond.). 343:757-760

17. Moore, K. L., N. L. Stults, S. Diaz, D. F. Smith, R. D. Cummings, A Varki, and R. P. McEver. 1992. Identification of a specific glycoprotein ligand for P-selectin (CD62) on myeloid cells. J. Cell Biol. 118:445-456.

18. Norgard, K. E., K. L. Moore, S. Diaz, N. L. Stults, S. Ushiyama, R. P. McEver, R. D. Cummings, and A. Varki. 1993. Characterization of a specific ligand for P-selectin on myeloid cells: a minor glycoprotein with sialylated Olinked oligosaccharides. J. Biol. Chem. 268:12764-12774.

19. Geng, J., K. L. Moore, A. E. Johnson, and R. P. McEver. 1991. Neutrophil recognition requires $\mathrm{Ca}^{2+}$-induced conformational change in the lectin domain of GMP-140. J. Biol. Chem. 266:22313-22318.

20. Geng, J., G. A. Heavner, and R. P. McEver. 1992. Lectin domain peptides from selectins interact with both cell surface ligands and $\mathrm{Ca}^{2+}$ Ions. J. Biol. Chem. 267:19846-19853.

21. Mulligan, M. S., M. J. Polley, R. J. Bayer, M. F. Nunn, J. C. Paulson, and P. A. Ward. 1992. Neutrophil-dependent acute lung injury. Requirement for P-selectin (GMP-140). J. Clin. Invest. 90:1600-1607.

22. DeForge, L. E., J. S. Kenney, M. L. Jones, J. S. Warren, and D. G. Remick. 1992. Biphasic production of IL-8 in lipopolysaccharide (LPS)-stimulated human whole blood: separation of LPS- and cytokine-stimulated components using antitumor necrosis factor and anti-IL-1 antibodies. J. Immunol. 148:2133-2141.

23. Mulligan, M. S., J. Varani, M. K. Dame, C. L. Lane, C. W. Smith, D. C. Anderson, and P. A. Ward. 1991. Role of endothelial-leukocyte adhesion molecule 1 (ELAM-1) in neutrophil-mediated lung injury in rats. J. Clin. Invest. 88:13961406.

24. Jaffe, E. A. 1984. Culture and identification of large vessel endothelial cells. In Biology of Endothelial Cells. E. A. Jaffe, editor. Martinus Nijoff, the Hague, 1-13.

25. Vaporciyan, A. A., M. L. Jones, and P. A. Ward. 1993. Rapid analysis of leukocyte-endothelial adhesion. J. Immunol. Methods. 159:93-100.

26. Mulligan, M. S., A. A. Vaporciyan, M. Miyasaka, T. Tamatani, and P. A. Ward. 1993. Tumor necrosis factor $\alpha$ regulated in vivo intrapulmonary expression of ICAM-1. Am. J. Pathol. 142:1739-1749.

27. Huey, R., and T. E. Hugli. 1985. Characterization of a C5a receptor on human polymorphonuclear leukocytes (PMN). J. Immunol. 135:2063-2068.

28. Rollins, T. E., and M. S. Springer. 1985. Identification of the polymorphonuclear leukocyte C5a receptor. J. Biol. Chem. 260:7157-7160.

29. Gerard, N. P., M. K. Hodges, J. M. Drazen, P. F. Weller, and C. Gerard. 1989. Characterization of a receptor for $\mathrm{C} 5 \mathrm{a}$ anaphylatoxin on human eosinophils. J. Biol. Chem. 264:1760-1766.

30. Chomczynski, P., and N. Sacchi. 1987. Single-step method of RNA isolation by acid guanidinium thiocyanate-phenol-chloroform extraction. Anal. Biochem. 162:156-159.

31. Gerard, C., D. E. Chenoweth, and T. E. Hugli. 1981. Response of human neutrophils to $\mathrm{C} 5 \mathrm{a}$ : a role for the oligosaccharide moiety of human $\mathrm{C} 5_{\text {des Arg-74 }}$ but not of C5a in biologic activity. J. Immunol. 5:1978-1982.

32. Murphy, H. S., J. A. Shayman, G. O. Till, M. Mahrougui, C. B. Owens, U. S. Ryan, and P. A. Ward. 1992. Superoxide responses of endothelial cells to C5a and TNF- $\alpha$ : divergent signal transduction pathways. Am. J. Physiol. 263:L51 L59.

33. Friedl, H. P., G. O. Till, U. S. Ryan, and P. A. Ward. 1989. Mediatorinduced activation of xanthine oxidase in endothelial cells. FASEB (Fed. Am. Soc. Exp. Biol.) J. 3:2512-2518.

34. Tonnesen, M. G., L. A. Smedly, and P. M. Henson. 1984. Neutrophilendothelial cell interactions. Modulation of neutrophil adhesiveness induced by complement fragments C5a and C5a des arg and formyl-methionyl-leucyl-phenylalanine in vitro. $J$. Clin. Invest. 74:1581-1592.

35. Zimmerman, G. A., and H. R. Hill. 1984. Inflammatory mediators stimulate granulocyte adherence to cultured endothelial cells. Thromb. Res. 35:203-217.

36. Hoover, R. L., R. Folger, W. A. Haering, B. R. Ware, and M. J. Karnovsky. 1980. Adhesion of leukocytes to endothelium: roles of divalent cations, surface charge, chemotactic agents and substrate. J. Cell. Sci. 45:73-86.

37. Kew, R. R., and R. O. Webster. 1988. Gc-globulin (vitamin D-binding protein) enhances the neutrophil chemotactic activity of C5a and C5a des arg. $J$. Clin. Invest. 82:364-369.

38. Perez, H. D., E. Kelly, D. Chenoweth, and F. Elfman. 1988. Identification of the C5a des arg cochemotaxin. Homology with vitamin D-binding protein (group specific component globulin). J. Clin. Invest. 82:360-363.

39. Gerard, C., and T. E. Hugli. 1981. Identification of classical anaphylatoxin as the des-Arg form of the C5a molecule: evidence of a modulator role for the oligosaccharide unit in human des-Arg ${ }^{74}$-C5a. Proc. Natl. Acad. Sci. USA. 78:1833-1837.

40. Marder, S. R., D. E. Chenoweth, I. M. Goldstein, and H. D. Perez. 1985 Chemotactic responses of human peripheral blood monocytes to the complementderived peptides C5a and C5a des arg. J. Immunol. 134:3325-3331.

41. Marks, R. M., R. F. Todd III, and P. A. Ward. 1989. Rapid induction of neutrophil-endothelial adhesion by endothelial complement fixation. Nature (Lond.). 339:314-317.

42. Goldstein, I. M. 1988. Complement: biologically active products. In Inflammation: Basic Principles and Clinical Correlates. J. I. Gallin, I. M. Goldstein, and R. Synderman, editors. Raven Press, New York. 55-74.

43. Zimmerman, G. A., S. M. Prescott, and T. M. McIntyre. 1992. Endothelial cell interactions with granulocytes: tethering and signaling molecules. Immunol. Today. 13:93-100.

44. Lorant, D. E M. K Topham, R. E. Whatley, R. P. McEver, T. M. McIntyre, S. M. Prescott, and G. A. Zimmerman. 1993. Inflammatory roles of Pselectin. J. Clin. Invest. 92:559-570.

45. Lindberg, C., F. Marceau, R. Huey, and T. E. Hugli. 1986. Anaphylatoxin C5a fails to promote prostacyclin release in cultured endothelial cells from human umbilical veins. Immunopharmacology. 12:135-143. 